\title{
A Concise Review of Surgical Exposures for Revision Knee Arthroplasty
}

\author{
Ashish Anand, Raviraj Adala, Manish Kumar, J. Vijay Kumar Srinivas, Gautam Kodikal \\ Center for Joint Replacement Fortis Hospitals, Bangalore, India \\ Email: ashishanandortho@yahoo.com
}

Received November 28, 2011; revised January 28, 2012; accepted February 12, 2012

\begin{abstract}
Revision knee arthroplasty is fraught with complications such as delayed wound healing, arthrofibrosis, increased chances of infection, instability and extensor mechanism disruption. The key to avoiding these complications is to handle the soft tissue with care and to have an adequate surgical exposure at the same time. As the number of revisions has gone up, there has been a renewed interest in getting the basics right to have an adequate surgical exposure. Numerous surgical approaches have been proposed and subsequently modified. We present a concise review of the various surgical approaches for a revision knee replacement.
\end{abstract}

Keywords: Knee; Arthroplasty; Revision; Exposures

\section{Introduction}

Total Knee Arthroplasty (TKA) is a fairly common procedure being performed across the world [1,2]. It has enjoyed considerable success over the years [3-6]. With increased life expectancy the number of knee replacements is set to see an exponential increase. Currently TKA is being done in relatively younger and active population [7-12]. As techniques have evolved the average lifespan of a well done TKA has increased and currently this is close to 20 years. With the current trend of increasing replacements in the younger population, number of TKA revisions will also increase as time dependent failure occurs [7-12]. The number of revisions is projected an increase of $601 \%$ from 2005 to 2030 [13]. Approx $50 \%$ of these revisions will take place in the younger age groups by 2011 [14]. The success rate of a well done primary TKA is $95 \%$ at 20 years follow up; however the success rate drops to $75 \%$ following revision surgery. The reason for marked change in the success rate is attributed to complexity of the case, more chances of complications and a more favorable implant survival profiles in the primary setting [15-23].

Prior to carrying out a revision knee replacement, it is prudent on the part of the surgeon to elucidate the mechanism of failure in each patient. This entails a thorough history taking and detailed physical examination. This is followed by preoperative planning and enumerating any need for special instrumentations, implants or allografts. Revision TKA must address soft tissue integrity and bone stock, which are often compromised and this dictates the choice of implants. The choice of implants include the nonlinked condylar constrained and linked rotating hinge designs. The reader is referred to specialized text for more details about the implants.

The surgeon must be well versed with performing revision surgeries and must be able to perform extensile exposures. Surgical technique in TKA relies on adequate exposure of the bony anatomical landmarks so that the components can be put in proper alignment. We present a review of the common approaches used in revision knee arthroplasty.

\section{Surgical Exposure}

The risk for wound dehiscence, wound edge necrosis and extensor mechanism complications is much higher in a revision setting [24]. Certain groups of patients are at much higher risk for wound necrosis including those who have had multiple procedures in the past, rheumatoid arthritis, vasculitis, infected knees and history of corticosteroid use [25].

Patients who have a higher chance of deep seated infection include those with diabetes, Rheumatoid arthritis, Psoriasis, renal failure and AIDS [25].

If one has to avoid the above mentioned complications, the surgeon should be familiar with the vascular anatomy of the knee. The reader is referred to selected articles [26-28] for an elaborate description. The patella is at higher risk of avascular necrosis as the primary TKA had already damaged its blood supply coming from three sides [29]. This includes the medial vessels, superior and inferior 
lateral genicular and recurrent anterior tibial artery.

The initial exposure for all revisions involves a standard medial parapatellar arthrotomy followed by excision of the scar tissue. If after the above incision exposure is limited with the attendant risk of patellar tendon avulsion, it is prudent for the surgeon to resort to one of the extensile approaches [30]. The type of exposure is dictated by, requirements of the case and surgeons comfort level with the technique.

\section{Coonse and Adams Approach}

This was first described in 1943 by Adams et al. [31]. This approach was used extensively till a modification was described by Insall in 1983 .This approach involves a V-Y turndown procedure of releasing the extensor mechanism proximal to the quadriceps attachment of the patella. This results in considerable scarring and weakness of the extensor mechanism. The potential benefit of V-Y quadricepsplasty over snip technique and tibial tubercle osteotomy is the ability to lengthen the quadriceps tendon, get a wide exposure while maintaining the patella tendontibial tubercle continuity. This approach was modified by Insall as it could not be extended from a standard medial parapatellar arthrotomy.

\section{Insalls Patellar Turndown}

This was first described by Insall [32] in 1983. After making a standard medial parapatellar arthrotomy if exposure is difficult a second incision at 45 degrees to the first one is made in the extensor mechanism. This gives a wide exposure and may be used to lengthen the extensor mechanism. It is contraindicated in conditions in which quality of the proximal tendinous portion is poor and contractility of the muscle is limited [33]. The dissection is carried down through the tendinous insertion of vastus lateralis and lateral retinaculum. The advantage of this is that the blood supply of the patella through the inferior lateral genicular artery is preserved [32,34]. The classical indication of this approach is a situation in which quadriceps snip is not good enough and proximal tibial osteopenia precludes use of a tibial tubercle osteotomy. Following repair knee is protected for 2 weeks in the post op period to allow the repair to heal [32]. Scott et al. [34] recommended a modification of the above approach by taking the lateral limb of the incision underneath the edge of the vastus lateralis through its tendinous insertion into the retinaculum rather than through the retinaculum. This is supposed to have a protective effect on the superior genicular artery. This view is not shared by Ritter et al. [35] who have shown that patellar fragmentation rate remains the same irrespective of the status of the superior genicular artery. At the time of the closure it is recommended to flex the knee to 90 degrees and reapproximate the tendon with number two nonabsorbable suture. This provides V-Y lengthening of the tendon. Post operatively patient has an extensor lag following either of the approaches but this causes little functional impairment [34].

\section{Rectus Snip}

It also goes by the name of quadriceps snip. The credit for this approach again goes to Insall. After having described modification of Quadriceps turndown in 1983, Insall used it till 1988 for many of the revision cases. It was at this time that he noticed that the proximal portion of the quadriceps had been transected in an oblique fashion and that it afforded excellent exposure. Closure was easy and there were no complications [36]. The technique involves using the previous skin incision or the lateral most of the incision. The deep incision involves a standard medial parapatellar arthrotomy. The quadriceps snip portion of the exposure involves an incision through the proximal part of the tendon, beginning at the proximal limit of the parapatellar incision and directed proximal and laterally. This helps in mobilization of the patella in a distal and lateral fashion. Occasionally a lateral retinacular release may be added to help in patellar eversion. The benefit of the snip procedure is that it preserves the blood supply coming from the lateral geniculate artery.

In case the exposure is insufficient after the above technique then a quadriceps turndown may be carried out. A thorough literature search failed to reveal use of both turndown and snip in the same case. If one is reluctant to use the Quadriceps turndown after a snip procedure, one can supplement the snip with tibial tubercle osteotomy.

Rectus snip is safe and simple to perform and there have been no differences in quadriceps strength compared to contralateral knee replacements [34]. The disadvantage is that it might require supplemental techniques if exposure is not good enough.

\section{Tibial Tubercle Osteotomy}

This technique was described by Dolin [37] in 1983. In the original described technique [36] the size of the fragment was $4.5 \mathrm{~cm}$ and it was fixed with a screw. In the series by Dolin a $23 \%$ complication rate was described which included non union in $11 \%$ and tendon rupture in $4 \%$. Exposure in revision knees can be accomplished by transaction of the quadriceps tendon above the patella $[31,34,38]$ but if one requires repeated entries then this can seriously compromise quadriceps function [39]. This is attributed to scarring and fibrosis. Biomechanical studies have shown that during active knee extension tensile forces are higher in the quadriceps tendon than in the patellar tendon, so any release inferior to the patella is less likely to fail [40]. Other authors have also reported variable success rate with this technique [41,42]. The most 
popular techniques have been popularized by Whiteside [43]. It offers the most extensive exposure to the knee in patients with severe quadriceps contracture and it is especially useful for patients of fibrous ankylosis and in cases of knee arthrodesis

In technique proposed by Whiteside the size of the fragment is $8-10 \mathrm{~cm}$, fixed with wires and allowing the use of canal filling stems. After a standard medial parapatellar arthrotomy if exposure is difficult a tubercle osteotomy is done. It is done with an oscillating saw and done from the medial to lateral side. A curved osteotome is used to make a transverse proximal cut above the attachment of the patellar tendon. One needs to preserve a proximal bone shell above the tubercle to prevent proximal migration. The size of the osteotomized fragment is $8 \mathrm{~cm}$ in length, $2 \mathrm{~cm}$ wide and $1 \mathrm{~cm}$ thick. The lateral attachments of the muscles and periosteum are left intact. To prevent the stress riser effect and oblique saw cut is made at the distal end of the osteotomized fragment.

Postoperatively fixation of the fragment can be done with screws [44]. The complication rate following screw fixation is higher $[42,44]$. The preferred method of fixation as per Whiteside is with two or three circlage wires .The drill holes are placed along the lateral edge of the tibial tubercle and directed obliquely upwards to the posteromedial corner. After passing the wires through these holes they are twisted down on the tuberosity fragment. Post operatively early range of motion and weight bearing are encouraged [45]. Occasionally it may be necessary to shift the fragment approximately by $1-2 \mathrm{~cm}$ [40]. Whiteside [45] reported his results with 136 osteotomies. No further exposure was required and mean postoperative range was 93.7 degrees. There were two avulsion fractures but that did not compromise function. Occasionally with compromised skin there might be penetration with the wires. Ritter et al. have reported fractures of proximal tibia in two of the nine cases [46].

This osteotomy is contraindicated in osteoporosis, large tibial bone defects, and scarred extensor mechanism [47].

\section{Medial Epicondylar Osteotomy}

Usually mobilization of the extensor mechanism by either of the above mentioned techniques is sufficient to give a wide exposure. Occasionally if the exposure is tight then one must release capsular attachments to the distal femur. This is accomplished by medial epicondylar osteotomy. After the standard medial parapatellar arthrotomy knee is placed in a fig of 4 position and flexed to 90 degrees. In this techniques described by Engh et al., $1 \mathrm{~cm}$ of medial epicondyle fragment is chiseled off the femur thereby maintaining attachment of adductor Magnus proximally and medial collateral ligament distally. If needed posteromedial capsule can be stripped further. The dis- section is carried out posteriorly and laterally around femur and tibia and knee is opened by externally rotating the knee and applying a valgus stress [48].

\section{Femoral Peel}

One other alternative in cases where capsular release is required is femoral peel described by Windsor and Insall [38]. This involves exposure around the medial and lateral corners of the femur by carrying out a subperiosteal elevation of the medial and lateral collateral ligaments. By stripping the post capsule a wide exposure is obtained. If the situation demands the origins of medial and lateral gastric can be released.

\section{Extensor Mechanism Tenolysis}

This technique was described by Sharkey et al. [49]. This involves a standard medial parapatellar arthrotomy followed by a complete synovectomy. Any adhesions between patellar tendon and upper pole of tibial tuberosity they are released. The patellar fat pad and the peripatellar fibrotic tissue are excised. Any adhesions in the lateral gutter are debrided and scar tissue is removed. The Quadriceps adhesions are debrided thereby exposing the tenosynovium of the quadriceps tendon and anterior femur. At this stage patella is everted and knee is flexed. If exposure appears tight at this stage then one can utilize any of the above mentioned methods to get additional exposure. In there study the authors reported there observations on 198 patients. Range of motion was 1.6 degrees to 103.8 degrees. There were no cases of delayed wound healing, skin necrosis or avascular necrosis of patella. only two patients were noted to have extensor lag of more than 5 degrees. The imp complications were Peripatellar fibrosis requiring arthroscopy (7.2\%), haematoma (4.8\%), manipulation under anesthesia (3.9\%), patellar subluxation (1.4\%) [49].

\section{Banana Peel Method}

This technique was described by Lahav et al. [50]. Initial exposure of the extensor mechanism is via the previously used skin incision .This is followed with a standard medial parapatellar arthrotomy to expose the knee joint. A quadriceps snip is done proximally [32]. A meticulous sharp dissection is done on the anterior tibia and medial to patellar tendon-this is the site of origin of the peel. At this stage patella is everted using minimal force. The periosteal sleeve along with the patellar tendon is peeled of the tibia as a single continuous layer. This is the most critical step as a meticulous release of the single sleeve with the attachment of patellar tendon maintains the extensor mechanism as a unit.

The added advantage is that one can extend the release as much distally and laterally as required for a complete 
exposure of the components. Lahav et al. have reported there observations on 102 patients. At a mean follow up of 39 months (range 24 - 56 months) the mean Knee Society score was 176 (range 95 - 200), mean postoperative score was 106 degrees. None of the patients had loss of extension and there were no disruptions of the extensor mechanism.

\section{Summary}

With the population aging across the globe and also the trend of doing TKA in younger patients, the number of revisions is set to see an exponential increase. Not all surgeons are well versed in tackling this complex scenario. To ensure a good outcome it is prudent that surgeons do a thorough pre operative assessment so as to have a good exposure at the time of surgery. One has to be familiar with all the approaches as one single approach cannot be recommended for all patients.

\section{REFERENCES}

[1] J. N. Insall, R. Binazzi, M. Soudry and L. A. Mestriner, “Total Knee Arthroplasty," Clinical Orthopaedics and Related Research, Vol. 192, No. 1, 1985, pp. 13-22.

[2] J. A. Rand and D. M. Ilstrup, "Survivorship Analysis of Total Knee Arthroplasty. Cumulative Rates of Survival of 9200 Total Knee Arthroplasties," Journal of Bone and Joint Surgery, Vol. 73, No. 3, 1991, pp. 397-409.

[3] R. L. Barrack, "Evolution of the Rotating Hinge for Complex Total Knee Arthroplasty,” Clinical Orthopaedics and Related Research, Vol. 392, No. 11, 2001, pp. 292-299. doi:10.1097/00003086-200111000-00038

[4] R. A. Berger, A. G. Rosenberg, R. M. Barden, M. B. Sheinkop, J. J. Jacobs and J. O. Galante, “Long Term Follow-Up of the Miller Galante Total Knee Replacement," Clinical Orthopaedics and Related Research, Vol. 388, No. 7, 2001, pp. 58-67.

[5] N. Hernigou, G. Mathieu, P. Filippini and A. Demoura, "Intra and Post Operative Fractures of the Femur in Total Knee Arthroplasty: Risk Factors in 32 Cases in French,” Revue de Chirurgie Orthopédique et Réparatrice de l'Appareil Moteur, Vol. 92, No. 2, 2006, pp. 140-147. doi:10.1016/S0035-1040(06)75699-9

[6] E. M. Keating, J. B. Meding, P. M. Faris and M. A. Ritter, "Long Term Follow-Up of Non-Modular Total Knee Replacements,” Clinical Orthopaedics and Related Research, Vol. 404, No. 11, 2002, pp. 34-39. doi:10.1097/00003086-200211000-00007

[7] D. R. Diduch, J. N. Insall, W. N. Scott, G. R. Scuderi and D. Rodrigues, "Total Knee Replacements in Young Active Patients," Journal of Bone and Joint Surgery, Vol. 79A, No. 4, 1997, pp. 571-582.

[8] F. Ewald and M. J. Christie, "Results of Cemented Total Knee Replacement in Young Patients,” Orthopedic Transactions, Vol. 11, No. 7, 1987, p. 442.

[9] D. S. Hungerford, K. A. Krackow and R. V. Kenna, “Ce- mentless Total Knee Replacement in Patients 50 Years Old and under," Orthopedic Clinics of North America, Vol. 20, No. 2, 1989, pp. 131-145.

[10] S. H. Stern, M. K. Bowen, J. N. Insall and J. R. Scuderi, "Cemented Total Knee Arthroplasty for Gonarthrosis in Patients 55 Years or Younger,” Clinical Orthopaedics and Related Research, Vol. 260, No. 11, 1990, pp. 124-129.

[11] M. J. Stuart and J. A. Rand, "Total Knee Arthroplasty in the Young Adult,” Orthopedic Transactions, Vol. 11, 1987, pp. 441-442.

[12] S. D. Stulberg, "Bi/Tricompartmental Degenerative Knee Disease in the Young Patient,” Journal of Orthopaedics, Vol. 18, No. 9, 1995, pp. 899-901.

[13] S. Kurtz, K. Ong, E. Lau, F. Mowat and M. Halpern, "Projections of the Primary and Revision Hip and Knee Arthroplasty in the United States from 2005 to 2030, Journal of Bone and Joint Surgery, Vol. 89, No. 4, 2007, pp. 780-785. doi:10.2106/JBJS.F.00222

[14] S. M. Kurtz, E. Lau, K. Ong, K. Zhao, M. Kelly and K. J. Bozic, "Future Young Patient Demand for Primary and Revision Joint Replacement: National Projections from 2010 to 2030," Clinical Orthopaedics and Related Research, Vol. 467, No. 10, 2009, pp. 2606-2612. doi:10.1007/s11999-009-0834-6

[15] G. R. Scuderi, J. N. Insall, R. E. Windsor and M. C. Moran, "Survivorship of Cemented Knee Replacements," Journal of Bone and Joint Surgery, Vol. 71, No. 5, 1989, pp. 798-803.

[16] M. A. Ritter, E. Campbell, P. M. Faris and E. M. Keating, "Long Term Survival Analysis of Posterior Cruciate Condylar Total Knee Arthroplasty: Ten Year Evaluation,” Journal of Arthroplasty, Vol. 4, No. 4, 1989, pp. 293-296. doi:10.1016/S0883-5403(89)80029-4

[17] J. Wright, F. C. Ewald, P. S. Walker, W. H. Thomas, R. Poss and C. B. Sledge, "Total Knee Arthroplasty with the Kinematic Prosthesis. Results after Five to Nine Years: A Follow-Up Note,” Journal of Bone and Joint Surgery, Vol. 72, No. 7, 1990, pp. 1003-1009.

[18] S. H. Stern and J. N. Insall, "Posteriorly Stabilized Results after Follow up of 9 Years," Journal of Bone and Joint Surgery, Vol. 74, No. 7, 1992, pp. 980-986.

[19] C. S. Ranawat, W. F. Flynn Jr., S. Saddler, K. K. Hansraj and M. J. Maynard, "Long Term Results of Total Condylar Knee Arthroplasty: A Fifteen Year Survivorship Study,” Clinical Orthopaedics and Related Research, Vol. 286, No. 1, 1993, pp. 94-102.

[20] M. A. Ritter, S. A. Herbit, E. M. Keating, P. M. Faris and J. B. Meding, "Long Term Survival Analysis of Post Cruciate Retaining Total Condylar Knee Arthroplasty,” Clinical Orthopaedics and Related Research, Vol. 309, No. 12, 1994, pp. 136-148.

[21] A. L. Malkani, J. A. Rand, R. S. Bryan and S. L. Wallrichs, "Total Knee Arthroplasty with the Kinematic Condylar Prosthesis,” Journal of Bone and Joint Surgery, Vol. 77A, No. 3, 1995, pp. 423-431.

[22] K. P. Emerson, C. J. Moran and I. M. Pinder, "Survivorship Analysis of the Kinematic Stabilizer Total Knee Replacement; 10 to 14 Year Follow up," Journal of Bone and Joint Surgery, Vol. 78B, No. 3, 1996, pp. 441-446. 
[23] D. J. Weir, C. G. Moran and I. M. Pinder, "Kinematic Condylar Knee Arthroplasty: A Fourteen Year Survivorship Analysis of 208 Consecutive Cases,” Journal of Bone and Joint Surgery, 78 B, No. 6, 1996, pp. 907-911.

[24] J. A. Rand, B. F. Morrey and R. S. Bryan, "Patellar Tendon Rupture after Total Knee Arthroplasty,” Clinical Orthopaedics and Related Research, Vol. 244, No. 7, 1989, pp. 233238.

[25] A. S. Younger, C. P. Duncan and B. A. Masri, "Surgical Exposures in Revision Total Knee Arthroplasty,” Journal of the American Academy of Orthopaedic Surgeons, Vol. 6, No. 1, 1998, pp. 55-64.

[26] P. A. Haertsch, "The Blood Supply to the Skin of the Leg: A Post Mortem Investigation," British Journal of Plastic Surgery, Vol. 34, No. 4, 1981, pp. 470-477. doi:10.1016/0007-1226(81)90061-8

[27] R. S. Laskin, "Soft Tissue Techniques in Total Knee Replacement,” In: R. S. Laskin, Ed., Total Knee Replacement, Springer-Verlag, London, 1991, pp. 41-53.

[28] K. Vince, "Revision Knee Arthroplasty Technique,” Instructional Course Lectures, Vol. 42, 1993, pp. 325-339.

[29] R. Scapinelli, "Blood Supply of the Human Patella: Its Relation to Ischemic Necrosis after Fracture,” Journal of Bone \& Joint Surgery, British Volume, Vol. 49, No. 3, 1967, pp. 563-570.

[30] E. T. Habermann, “The Infected Total Knee Arthroplasty,” In: R. S. Laskin, Ed., Total Knee Replacement, Springer-Verlag, London, 1991, pp. 241-252.

[31] K. Coonse and J. D. Adams, “A New Operative Approach to the Knee Joint,” Gynecological Surgery, Vol. 77, No. 4, 1943, pp. 344-347.

[32] J. N. Insall, “Surgical Approaches,” In: J. N. Insall, R. E. Windsor, W. N. Scott, M. A. Kelly and P. Aglietti, Eds., Surgery of the Knee, 2nd Edition, Churchill Livingstone, New York, 1993, pp. 135-148.

[33] M. J. Stuart, “Anatomy and Surgical Approaches,” In: B. F. Morrey, Ed., Reconstructive Surgery of the Joints, Churchill Livingstone, New York, 1996, p. 1345.

[34] R. Scott and J. Siliski, "The Use of a Modified V-Y Quadricepsplasty during Total Knee Replacement to Gain Exposure and Improve Flexion in the Ankylosed Knee," Orthopedics, Vol. 8, No. 45, 1985, pp. 45-48.

[35] M. A. Ritter, S. A. Herbst, E. M. Keating, P. M. Faris and J. B. Meding, "Patellofemoral Complications Following Total Knee Arthroplasty: Effect of Lateral Release and Sacrifice of the Superior Lateral Geniculate Artery," Journal of Arthroplasty, Vol. 11, 1996, pp. 368-372. doi:10.1016/S0883-5403(96)80024-6

[36] K. L. Garvin, G. S. Scuderi and J. N. Insall, "Evolution of the Quadriceps Snip," Clinical Orthopaedics and Related Research, Vol. 321, No. 12, 1995, pp. 131-137.
[37] M. G. Dolin, "Osteotomy of the tibial tubercle in total knee replacement,” Journal of Bone \& Joint Surgery, Vol. 65, No. 6, 1983, pp. 704-706.

[38] R. E. Windsor and J. N. Insall, "Exposure in Revision Knee Arthroplasty: The Femoral Peel," Techniques in Orthopaedics, Vol. 3, No. 1, 1988, pp. 1-4.

[39] R. T. Trousdale, A. D. Hansen, J. A. Rand and T. D. Cahalan, "V-Y Quadricepsplasty in Total Knee Arthroplasty," Clinical Orthopaedics and Related Research, Vol. 286, No. 1, 1993, pp. 48-55.

[40] R. A. Denham and R. E. D. Bishop, "Mechanics of the Knee and Problems in Reconstructive Surgery," Journal of Bone \& Joint Surgery, Vol. 60B, No. 3, 1978, pp. 345-352.

[41] R. N. Levy, "Osteotomy of the Tibial Tubercle in Total Knee Replacement,” Journal of Bone \& Joint Surgery, Vol. 65A, No. 8, 1983, pp. 1207-1208.

[42] A. M. Wolff, D. S. Hungerford, K. A. Krackow and M. A. Jacobs, "Osteotomy of the Tibial Tubercle during Total Knee Replacement,” Journal of Bone \& Joint Surgery, Vol. 71A, No. 6, 1989, pp. 848-852.

[43] L. A. Whiteside and M. D. Ohl, “Tibial Tubercle Osteotomy for Exposure of the Difficult Total Knee Arthroplasty," Clinical Orthopaedics and Related Research, Vol. 260, No. 11, 1990, pp. 6-9.

[44] M. D. Ries and J. A. Richman, "Extended Tibial Tubercle Osteotomy in Total Knee Arthroplasty,” Journal of Arthroplasty, Vol. 11, No. 8, 1996, pp. 964-967. doi:10.1016/S0883-5403(96)80138-0

[45] L. Whiteside, "Exposure in Difficult Total Knee Arthroplasty Using a Tibial Tubercle Osteotomy,” Clinical Orthopaedics and Related Research, 1995, Vol. 32, No. 321, pp. 32-35.

[46] M. Ritter, “Complications Following Total Knee Arthroplasty,” Journal of Arthroplasty, 1996, Vol. 11, No. 1, pp. 11, 117-119. doi:10.1016/S0883-5403(96)80171-9

[47] M. J. Stuart, “Anatomy and Surgical Approaches,” In: B. F. Morrey, Ed., Reconstructive Surgery of the Joints, Churchill Livingstone, New York, Vol. 9, 1996, p. 1345.

[48] G. A. Rorabeck Engh and J. P. McCauley, “Joint Line Restoration and Flexion Extension Balance with Revision Total Knee Arthroplasty,” In: G. A. Engh and C. Rorabeck, Eds., Revision Knee Arthroplasty, Williams and Wilkins, Baltimore, 1997, p. 235.

[49] P. Sharkey, D. Homesley, S. Shastri, S. Jacoby and W. Hozack and R. Rothman, "Results of Revision Total Knee Arthroplasty after Exposure of the Knee with Extensor Mechanism Tenolysis,” Journal of Arthroplasty, Vol. 19. No. 6, 2004, pp. 751-756. doi:10.1016/j.arth.2003.12.084

[50] A. Lahav and A. Hoffman, "The 'Banana Peel' Exposure Method in Revision Total Knee Arthroplasty," American Journal of Orthopedics, Vol. 36, No. 10, 2007, pp. 526-529. 